\title{
CORRIGENDA
}

\section{Liver-related safety assessment of green tea extracts in humans: a systematic review of randomized controlled trials}

T Isomura, S Suzuki, H Origasa, A Hosono, M Suzuki, T Sawada, S Terao, Y Muto and T Koga

European Journal of Clinical Nutrition (2016) 70, 1340; doi:10.1038/ejcn.2016.165

Correction to: European Journal of Clinical Nutrition (2016) $\mathbf{7 0 ,}$ 1221-1229; doi:10.1038/ejcn.2016.78; published online 18 May 2016

Since the publication of this article, the authors have noticed an error in the abstract. The following sentence is correct: 'The summary odds ratio, estimated using a meta-analysis method for sparse event data, for intervention compared with placebo was 2.1 (95\% confidence interval: 0.5-9.8).' The PDF and online versions have been amended.

The authors apologise for any inconvenience caused.

\section{A systematic review and meta-analysis of randomized controlled trials of the effect of barley $\beta$-glucan on LDL-C, non-HDL-C and apoB for cardiovascular disease risk reduction $^{\mathrm{i} \text {-iv }}$}

HVT Ho, JL Sievenpiper, A Zurbau, S Blanco Mejia, E Jovanovski, F Au-Yeung, AL Jenkins and V Vuksan

European Journal of Clinical Nutrition (2016) 70, 1340; doi:10.1038/ejcn.2016.129

Correction to: European Journal of Clinical Nutrition (2016) 70, 1239-1245; doi: 10.1038/ejcn.2016.89; published online 8 June 2016

Since the publication of this article, the authors have noticed that the author S Blanco Mejia's name was displayed incorrectly. The article PDF and html versions have been corrected.
The authors apologise for any inconvenience caused. 